\title{
Influência do uso de resíduo de quartzito na expansão por umidade de massas de revestimentos cerâmicos planos
}

\section{(Influence of use of quartzite waste in moisture expansion of masses for ceramic tiles)}

\author{
R. R. Medeiros, W. P. Gonçalves, J. M. Cartaxo, H. S. Ferreira, G. A. Neves, H. C. Ferreira \\ Programa de Pós-Graduação em Ciência e Engenharia de Materiais, Universidade Federal de Campina \\ Grande, Av. Aprígio Veloso 882, Campina Grande, PB 58429-900 \\ rosinaldo.medeiros@ufrr.br,wherllyson@yahoo.com.br,julianamelo25@gmail.com,hebersivini@gmail.com, \\ gelmires.neves@ufcg.edu.br,heber.carlos@ufcg.edu.br
}

\begin{abstract}
Resumo
A expansão por umidade (EPU) é caracterizada por um aumento das dimensões físicas do corpo cerâmico quando em contato com a água na forma líquida ou de vapor. O fenômeno de EPU pode contribuir para o surgimento de patologias graves em revestimentos cerâmicos como trincas, deslocamentos ou danos mais severos. Este trabalho objetivou estudar o problema da EPU em massas cerâmicas aditivadas com resíduos de quartzito para uso em revestimentos utilizando a técnica de dilatometria e a resistência mecânica à flexão em três pontos. As matérias-primas foram beneficiadas e caracterizadas através de ensaios de análise granulométrica por difração a laser, plasticidade, análise química, análise termodiferencial, termogravimétrica e difração de raios X. Os resultados evidenciaram que a adição de resíduos de quartzito de maneira geral elevou os valores de EPU para corpos queimados em temperaturas inferiores a $1100{ }^{\circ} \mathrm{C}$. Para corpos queimados a $1200^{\circ} \mathrm{C}$ os resultados indicaram elevado comportamento mecânico e diminuição da EPU, sendo os melhores resultados para as massas aditivadas com $15 \%$ de quartzito.

Palavras-chave: EPU, resíduo de quartzito, revestimentos cerâmicos planos.
\end{abstract}

\begin{abstract}
The moisture expansion (ME) is characterized as an increase in physical dimensions of ceramic body when in contact with water (liquid or vapor). The ME phenomenon may contribute to the appearance of serious pathology in ceramic tiles such as cracks, detachment or more severe damages. This work aimed to study the problem of ME in ceramic masses added with quartzite waste for use in tiles using the dilatometry and three-point flexural strength methods. The raw materials were processed and characterized by laser diffraction particle size analysis, plasticity, chemical analysis, thermogravimetric and differential thermal analysis, and X-ray diffraction. The results showed that the addition of quartzite waste generally elevated ME values for bodies fired at temperatures below $1100{ }^{\circ} \mathrm{C}$. For bodies fired at $1200{ }^{\circ} \mathrm{C}$ the results indicated high mechanical performance and ME decrease, and the best results for additive formulations was $15 \%$ of quartzite.
\end{abstract}

Keywords: moisture expansion, quartzite waste, ceramic tiles.

\section{INTRODUÇÃO}

A expansão por umidade (EPU) é um fenômeno complexo e pode ser definido como um termo técnico utilizado para designar a expansão sofrida por materiais cerâmicos quando em contato com a água na forma líquida ou de vapor. Essa expansão quando elevada pode levar ao comprometimento dos revestimentos cerâmicos levando ao seu fissuramento e mesmo deslocamento ou destacamento. No caso do deslocamento a aderência das placas cerâmicas em pisos e alvenarias fica comprometida e dessa forma leva ao seu destacamento, como também ao gretamento de peças esmaltadas quando as tensões geradas pelas deformações nas peças excedem os limites de resistência mecânica da camada vítrea ou esmalte. A EPU ainda é pouco estudada no Brasil, principalmente em revestimentos cerâmicos, e diversos pesquisadores entendem que há necessidade de estudos sistemáticos deste fenômeno com o intuito de melhor conhecer os fatores envolvidos [1,2].

A EPU começou a ser discutida na literatura cerâmica na década de 20 do século passado [3]; desde então muitos estudos foram realizados analisando suas causas, tais como: composição química, temperatura de queima e características microestruturais. Este fenômeno atraiu a atenção de vários pesquisadores e cientistas, principalmente na África do Sul, Austrália, alguns países da Europa e Estados Unidos. O grande interesse nesse fenômeno devese à constatação que, junto com o ataque de sais, a EPU é a causa mais comum da deterioração de revestimentos cerâmicos em todo mundo [2, 4]. Com relação aos trabalhos 
sobre EPU que merecem destaque, podem-se citar os estudos [5-9] que pesquisaram diversos aspectos da EPU. Suas causas não eram bem conhecidas até 1955 , quando Smith [5] introduziu, pela primeira vez, a teoria de que a EPU é causada pela diminuição da tensão superficial dos corpos quando a umidade é adsorvida à sua superfície. Esta tensão é apontada como a força motriz do processo [10]. Apesar da reconhecida ação maléfica provocada pela EPU, ainda há um longo caminho a se percorrer para que o fenômeno seja plenamente entendido. As fases amorfas são as mais reativas frente à umidade e, por conseguinte, mais susceptíveis de provocarem elevada EPU nos corpos cerâmicos, enquanto que as fases vítreas e cristalinas são, nesta ordem, menos sensíveis à umidade $[5-8,10]$.

No Brasil também foram observadas manifestações de falhas de peças cerâmicas relacionadas ao fenômeno da EPU, com estudos relatando principalmente gretamentos, destacamentos e quebras de revestimentos cerâmicos. No final do século passado verificou-se, através de estudos realizados na Universidade Federal de Campina Grande por iniciativa da Unidade Acadêmica de Engenharia de Materiais, que a EPU poderia estar associada às falhas estruturais de alvenarias no Nordeste do país e desabamento de prédios na Região Metropolitana do Recife-PE [11]. Estudos indicam que há um comprometimento estrutural de cerca de seis mil edifícios na Grande Recife, o que evidencia a grande importância do conhecimento da existência de correlações entre resistência dos corpos cerâmicos e o desenvolvimento da EPU [12]. Nesse sentido, é interessante destacar alguns conceitos utilizados na determinação da EPU [12]. EPU "atual" é a que se caracteriza pela efetiva expansão do corpo cerâmico desde a sua fabricação até o momento do seu emprego, enquanto a EPU "futura" refere-se a toda sua vida útil desde sua fabricação. A determinação da EPU geralmente é feita através da medição do corpo de prova antes e após requeima. Também é possível o uso da dilatometria para a determinação da EPU. Para determinação da EPU do corpo cerâmico deve-se submetê-lo ao ensaio de autoclavagem (ASTM [13]), imersão em água fervente (ISO [14] e ABNT 13818 [15]) ou apenas imersão em água ou exposição ao seu vapor. Estas normas indicam que a EPU máxima para blocos cerâmicos (tijolos) seja de $0,3 \mathrm{~mm} / \mathrm{m}(0,03 \%)$ e para revestimentos seja de $0,6 \mathrm{~mm} / \mathrm{m}(0,06 \%)$. Na determinação da EPU por dilatometria, as curvas dilatométricas registram as alterações dimensionais das amostras, sejam elas simplesmente ligadas aos coeficientes de dilatação (térmica) e/ou devidas a diversos fenômenos que podem ocorrer durante o aquecimento, entre os quais: perda de água livre e adsorvida, hidroxilas e transformações estruturais, tais como sinterização, formação de fases líquidas viscosas e fluência $[1,16,17]$. Com a eliminação da água livre e adsorvida no material o ensaio é realizado limitando-se à temperatura máxima de aquecimento em $550{ }^{\circ} \mathrm{C}$, para que também não ocorram alterações microestruturais no material, como a transformação de quartzo alfa em quartzo beta que ocorre a $573{ }^{\circ} \mathrm{C}$.

Embora a EPU seja um tema a muito discutido, existem algumas controvérsias no que diz respeito aos métodos utilizados para sua determinação. No que se refere às temperaturas de requeima, grande parte da discussão está voltada à questão da possível influência da inversão do quartzo $\left(573{ }^{\circ} \mathrm{C}\right)$ na determinação da EPU e no fato de que a cinética de re-expansão dos corpos requeimados em temperaturas da ordem de $550{ }^{\circ} \mathrm{C}$ não é igual à cinética de expansão natural $[14,15,18]$, e que requeimas entre 800 e $900{ }^{\circ} \mathrm{C}$ podem induzir a ressinterizações. No que tange a determinação da EPU futura a discussão se dá em torno do tipo de ensaio mais adequado. A autoclavagem é posta em dúvida por utilizar temperaturas e pressões bem acima das condições de serviço, podendo fornecer dados não realísticos [7]. Já o ensaio de fervura possui controvérsias por não propiciar, aparentemente, a obtenção da verdadeira expansão em potencial do material. Logo, na utilização de qualquer dos métodos deve-se definir precisamente os seus parâmetros, de modo a evitar discrepâncias entre os resultados obtidos em um mesmo ensaio $[14,15]$.

Com relação aos resíduos sólidos verifica-se que há uma crescente preocupação mundial devido ao seu grande volume e, também, à dificuldade de sua destinação final. Estes resíduos podem gerar custos adicionais e sérios problemas ambientais quando depositados em locais como aterros sanitários ou lixões, causando a degradação do solo, contaminação tanto do lençol freático quanto de mananciais e, também, a contaminação do ar. A incorporação de resíduos de várias atividades em produtos cerâmicos argilosos é uma alternativa tecnológica que pode contribuir para a redução do impacto ambiental $[14,19]$. Os resíduos podem ainda melhorar o processamento cerâmico, a qualidade da cerâmica e, ainda, contribuir para a redução do gasto energético na etapa de queima. Quando incorporados em quantidades significativas, contribuem para a redução do consumo de argilas, recurso natural não renovável [20]. Neste estudo foi utilizado, para incorporação às massas, o quartzito, que é uma rocha ornamental metamórfica e apresenta uma tendência a ser coesa, com estrutura cristalina densa. A variabilidade das características das argilas e massas, assim como o emprego de técnicas de processamento relativamente simples para fabricação de revestimento cerâmicos, facilita a incorporação de resíduos nas composições deste setor [21, 22]. Estudos têm comprovado que a incorporação de alguns resíduos permite a obtenção de peças com propriedades de acordo com o estabelecido pelas normas [23-25]. Assim, este trabalho teve por objetivo estudar o problema da EPU e o comportamento mecânico em massas cerâmicas incorporadas com resíduo de quartzito para uso na fabricação revestimentos cerâmicos.

\section{MATERIAIS E MÉTODOS}

As matérias-primas utilizadas neste trabalho foram: massa cerâmica fornecida por uma indústria cerâmica localizada no município de Boa Vista, Roraima; e resíduo proveniente do corte de placas de quartzito, fornecido por uma empresa de mineração localizada no município de 
Várzea, Paraíba. Inicialmente, as amostras passaram pelas seguintes etapas de beneficiamento: britagem em britador de mandíbula, moagem em moinho de bolas por $3 \mathrm{~h}$ e classificação em peneira ABNT $\mathrm{n}^{\circ} 200(0,074 \mathrm{~mm})$ e em seguida foram submetidas às caracterizações física, química e mineralógica. A caracterização das amostras foi efetuada por meio das seguintes técnicas: análise granulométrica por difração a laser (mod. 1064, Cilas,); limites de liquidez e de plasticidade, com base nas normas da ABNT [26, 27]; análise química por fluorescência de raios X (EDX 720, Shimadzu); difração de raios X (D6000, Shimadzu), com radiação $\mathrm{CuK \alpha}(40 \mathrm{kV}, 30 \mathrm{~mA})$ e velocidade do goniômetro de $2 \%$ min e passo de $0,02^{\circ}$, com faixa de $5^{\circ}$ a $60^{\circ}$ para a massa e $5^{\circ}$ a $80^{\circ}$ para o resíduo.

Foram analisadas quatro massas, uma sem resíduo e as outras contendo diferentes percentuais do resíduo de quartzito; na Tabela I estão apresentadas as composições estudadas. As composições das massas com e sem adição de resíduo foram umedecidas com $7 \%$ de água, em seguida homogeneizadas em moinho de bolas por $3 \mathrm{~h} \mathrm{e}$, posteriormente, permaneceram em repouso por $24 \mathrm{~h}$. As massas cerâmicas foram conformadas por prensagem uniaxial (1,0 MPa por $10 \mathrm{~s}$, seguida de pressão de 19,0 MPa por $20 \mathrm{~s}$ ) em uma prensa hidráulica (CT-335, Servitech), para obtenção de corpos de prova retangular com $50 \mathrm{~mm}$ x $15 \mathrm{~mm}$ de dimensões. Após conformação, foram secos em estufas a $110{ }^{\circ} \mathrm{C}$ por $24 \mathrm{~h}$, em seguida queimados nas temperaturas de $850,900,950,1100$ e $1200{ }^{\circ} \mathrm{C}$ à taxa de 2 ${ }^{\circ} \mathrm{C} / \mathrm{min}$ e patamar de queima de $120 \mathrm{~min}$; para esta etapa, utilizou-se um forno elétrico (FE50RP, Flyever). Os corpos de prova destinados à determinação da EPU foram cortados nas dimensões $0,7 \mathrm{~cm} \times 0,7 \mathrm{~cm} \times 5,0 \mathrm{~cm}$ e, após queima, foram resfriados naturalmente.

Foram analisadas as seguintes propriedades físicomecânicas: retração linear de queima analisada com base na variação dimensional linear dos corpos de prova sinterizados; porosidade aparente e absorção de água avaliadas através do método de Arquimedes utilizando-se como fluido de imersão a água na temperatura ambiente; e tensão de ruptura à flexão em três pontos, utilizando-se uma máquina universal de ensaios mecânicos (Autograph AG-X $50 \mathrm{kN}$, Shimadzu) operando a uma velocidade de $0,5 \mathrm{~mm} / \mathrm{min}$ [13]. Para a determinação da EPU os corpos de prova foram submetidos ao processo de fervura por $24 \mathrm{~h}$, segundo metodologia descrita na ISO [14], ABNT
NBR [15]. A determinação da EPU foi efetuada através da técnica de dilatometria na qual todos os corpos de prova foram ensaiados em aparelho da BP Engenharia (RB3000-20), com velocidade de aquecimento de $150{ }^{\circ} \mathrm{C} / \mathrm{h}$ até $550{ }^{\circ} \mathrm{C}$, permanecendo nessa temperatura por 120 min, seguido de resfriamento natural até a temperatura ambiente. Em geral, utilizaram-se dois corpos de prova; no entanto, quando ocorreu diferença nos resultados maiores que $0,005 \%$, foi utilizado um terceiro corpo de prova. $\mathrm{O}$ resultado da expansão por umidade (EPU) foi a média de duas determinações para cada condição de ensaio. Neste estudo deu-se ênfase a EPU potencial.

Tabela I - Formulações das massas que foram utilizadas. [Table I - Formulations of the masses.]

\begin{tabular}{ccc}
\hline \multirow{2}{*}{ Formulação } & \multicolumn{2}{c}{ Componente (\%) } \\
& Argila & Quartzito \\
\hline $\mathrm{MI}+0 \mathrm{Q}$ & 100 & 0 \\
$\mathrm{MI}+5 \mathrm{Q}$ & 95 & 5 \\
$\mathrm{MI}+10 \mathrm{Q}$ & 90 & 10 \\
$\mathrm{MI}+15 \mathrm{Q}$ & 85 & 15 \\
\hline
\end{tabular}

\section{RESULTADOS E DISCUSSÃO}

A Tabela II ilustra a composição química das massas cerâmicas com e sem aditivação de resíduo de quartzito. Percebe-se que as amostras apresentaram como principais constituintes a sílica $\left(\mathrm{SiO}_{2}, 54-78 \%\right)$ e a alumina $\left(\mathrm{Al}_{2} \mathrm{O}_{3}\right.$, $11-28 \%$ ). A sílica foi proveniente da camada tetraédrica do argilomineral caulinita e dos minerais acessórios mica, feldspato e quartzo livre em sua forma natural mais pura. A alumina também teve associação com as fases mineralógicas supracitadas. Como o teor de ferro $\left(\mathrm{Fe}_{2} \mathrm{O}_{3}\right)$ foi abaixo de $5,0 \%$, as massas podem apresentar após queima uma coloração um pouco avermelhada [28]. Os teores de fundentes $\left(\mathrm{K}_{2} \mathrm{O}+\mathrm{Fe}_{2} \mathrm{O}_{3}+\mathrm{MgO}+\mathrm{CaO}\right)$ responsáveis pela formação de fase vítrea apresentaram valores superiores a $7,0 \%$. Esses valores têm importância pela capacidade de reduzir a temperatura de sinterização e aumentar a resistência na fabricação dos revestimentos cerâmicos, contribuindo para minimizar, de forma indireta, os efeitos da EPU [29].

$\mathrm{O}$ resíduo de quartzito apresentou a sílica $\left(\mathrm{SiO}_{2}\right)$ e a alumina $\left(\mathrm{Al}_{2} \mathrm{O}_{3}\right)$ como seus principais constituintes e em

Tabela II - Composição química (\% em massa) das massas cerâmicas e do resíduo de quartzito.

[Table II - Chemical composition (wt\%) of the ceramic masses and quartzite waste.]

\begin{tabular}{cccccccccc}
\hline Amostra & $\mathrm{SiO}_{2}$ & $\mathrm{Al}_{2} \mathrm{O}_{3}$ & $\mathrm{Fe}_{2} \mathrm{O}_{3}$ & $\mathrm{~K}_{2} \mathrm{O}$ & $\mathrm{TiO}_{2}$ & $\mathrm{CaO}$ & $\mathrm{MgO}$ & Outros & $\mathrm{PF}^{*}$ \\
\hline $\mathrm{MI}+0 \mathrm{Q}$ & 54,6 & 28,1 & 4,2 & 1,5 & 0,5 & - & 0,5 & 0,5 & 9,1 \\
$\mathrm{MI}+5 \mathrm{Q}$ & 56,6 & 26,8 & 3,4 & 1,5 & 0,4 & - & 0,8 & 1,7 & 8,7 \\
$\mathrm{MI}+10 \mathrm{Q}$ & 58,0 & 26,9 & 3,6 & 1,7 & 0,5 & - & 0,7 & 1,7 & 7,8 \\
$\mathrm{MI}+15 \mathrm{Q}$ & 59,5 & 26,0 & 3,4 & 1,9 & 0,4 & - & 0,8 & 0,7 & 7,7 \\
Quartzito & 78,1 & 11,4 & 1,4 & 5,1 & 0,1 & 0,9 & 0,9 & 0,5 & 1,5 \\
\hline
\end{tabular}

*PF - perda ao fogo. 


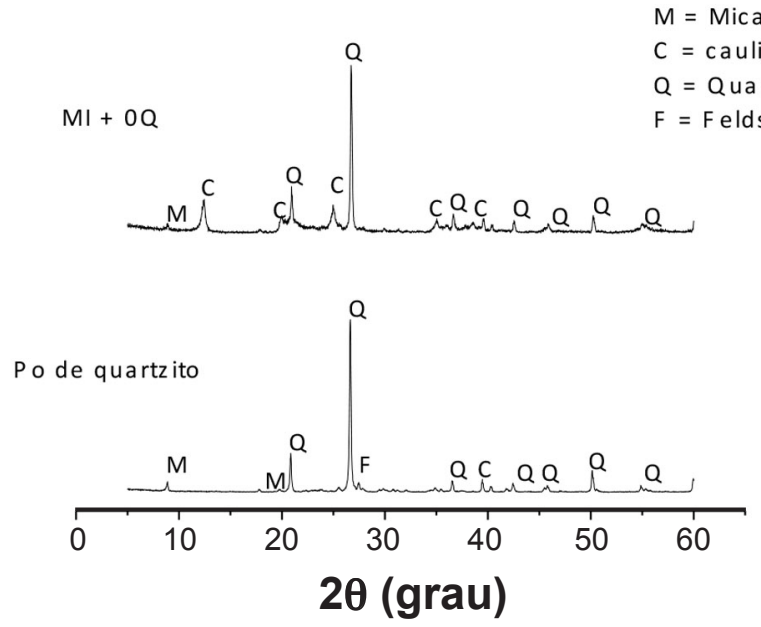

Figura 1: Difratogramas de raios $\mathrm{X}$ da amostra sem adição de resíduo $(\mathrm{MI}+0 \mathrm{Q})$ e do resíduo de quartzito.

[Figure 1: X-ray diffraction patterns of sample without residue $(M I+0 Q)$ and quartzite residue.]

menores proporções os óxidos de potássio $\left(\mathrm{K}_{2} \mathrm{O}\right)$, titânio $\left(\mathrm{TiO}_{2}\right)$, cálcio $(\mathrm{CaO})$, magnésio $(\mathrm{MgO})$ e ferro $\left(\mathrm{Fe}_{2} \mathrm{O}_{3}\right)$. Observou-se uma quantidade considerável de óxidos fundentes $\left(\mathrm{Fe}_{2} \mathrm{O}_{3}+\mathrm{K}_{2} \mathrm{O}+\mathrm{MgO}\right)$ de cerca de 6,53\%. Alguns pesquisadores $[25,29,30]$ estudaram a incorporação de diferentes tipos de resíduos de rochas ornamentais em massas cerâmicas e foram detectados na análise química dos resíduos teores de sílica e alumina similares aos encontrados neste trabalho. Pôde-se observar que, de acordo com a composição química mostrada na Tabela II, a massa industrial apresentou características similares às de argilas utilizadas para cerâmica branca [31].

A Fig. 1 ilustra os difratogramas de raios $\mathrm{X}$ das amostras de massa industrial e do resíduo de quartzito. Observou-se que amostras apresentaram as seguintes fases mineralógicas: mica (JCPDS 83-1808), caulinita (JCPDS 78-2110), feldspato (JCPDS 89-8573) e quartzo (JCPDS 46-1045). $\mathrm{O}$ argilomineral caulinita é um importante componente de massas cerâmicas, pois atua na conformação favorecendo a trabalhabilidade do material. $\mathrm{O}$ feldspato atua como fundente, contribuindo para a formação da fase vítrea, e o quartzo na redução de plasticidade e no controle dimensional da peça cerâmica. No resíduo de quartzito observaram-se as seguintes fases mineralógicas: quartzo (JCPDS 46-1045), feldspato (JCPDS 84-0710) e mica (JCPDS 83-1808).
Todos os minerais detectados no resíduo estão geralmente presentes nas matérias-primas utilizadas para a fabricação de pisos e revestimentos, tornando possível a sua incorporação. Os difratogramas de raios $\mathrm{X}$ das demais amostras não foram apresentados em virtude das fases cristalinas presentes terem sido mantidas, sendo variadas apenas as intensidades dos picos.

Na Tabela III estão contidos os resultados da distribuição granulométrica e as características de plasticidade das massas cerâmicas. Verificou-se que para a fração argila a percentagem de massa acumulada variou entre 31,12 e $35,71 \%$. A fração silte (diâmetro médio entre 2 e $20 \mu \mathrm{m}$ ) variou entre 61,21 e $63,70 \%$, e a areia $(>20 \mu \mathrm{m})$ entre 0,59 e 7,67\%. Em relação às características de plasticidade das massas estudadas, observou-se um decréscimo do índice de plasticidade com o acréscimo da adição de resíduo na composição; isso é justificado em virtude do resíduo de quartzito ser um material não plástico. Os limites de liquidez variaram entre 40,30 e $52,60 \%$ e foram em acordo com os limites definidos na literatura (30-60\%) [31] para massas utilizadas em produtos cerâmicos. Os valores do limite de plasticidade apresentaram variação entre 22,70 e $27,00 \%$, estando de acordo com os valores indicados na literatura (15-30\%) para produção de produtos cerâmicos por extrusão [32]. Os resultados do índice de plasticidade entre 17,30 e $28,00 \%$ classificaram as massas como altamente plástica por apresentarem valores acima de $15 \%$ [32]. Este é um dado acessório que é útil quando do processamento industrial dessa matéria-prima.

A Fig. 2 ilustra as curvas de análise térmica diferencial (ATD) e análise termogravimétrica das composições. Nas curvas de ATD das composições estudadas, verificouse que houve um pico endotérmico entre 104 e $108{ }^{\circ} \mathrm{C}$, característico da água livre e adsorvida no material, um grande pico endotérmico entre 573 e $580{ }^{\circ} \mathrm{C}$, característico da presença de hidroxilas da caulinita, e um pico exotérmico entre 949 e $967{ }^{\circ} \mathrm{C}$, característico da nucleação da mulita. Nas curvas termogravimétricas, verificou-se que houve perda de massa total entre 10 e $11,13 \%$ correspondente às perdas da água livre e adsorvida, hidroxilas da caulinita e outras perdas.

A Fig. 3 ilustra os difratogramas de raios $\mathrm{X}$ dos corpos cerâmicos das massas estudadas após queima a $1200^{\circ} \mathrm{C}$. A escolha desta temperatura se deu em virtude da ocorrência de menor EPU. As fases cristalinas observadas após a queima

Tabela III - Distribuição de tamanho de partículas e limites de Atterberg das massas cerâmicas.

[Table III - Particle size distribution and Atterberg limits of the ceramic masses.]

\begin{tabular}{ccccccc}
\hline \multirow{2}{*}{ Amostra } & \multicolumn{3}{c}{ Composição granulométrica (\%) } & \multicolumn{3}{c}{ Limites de Atterberg (\%) } \\
& $<2 \mu \mathrm{m}$ & $2-20 \mu \mathrm{m}$ & $>20 \mu \mathrm{m}$ & L.L.* & L.P.* & I.P.* \\
\hline $\mathrm{MI}+0 \mathrm{Q}$ & 35,71 & 63,70 & 0,59 & 52,60 & 24,60 & 28,00 \\
$\mathrm{MI}+5 \mathrm{Q}$ & 34,63 & 62,76 & 2,61 & 45,40 & 27,00 & 18,40 \\
$\mathrm{MI}+10 \mathrm{Q}$ & 33,48 & 61,95 & 4,57 & 40,30 & 23,00 & 17,30 \\
$\mathrm{MI}+15 \mathrm{Q}$ & 31,12 & 61,21 & 7,67 & 43,90 & 22,70 & 21,20 \\
\hline
\end{tabular}

*L.L. - limite de liquidez; L.P. - limite de plasticidade; I.P. - índice de plasticidade. 

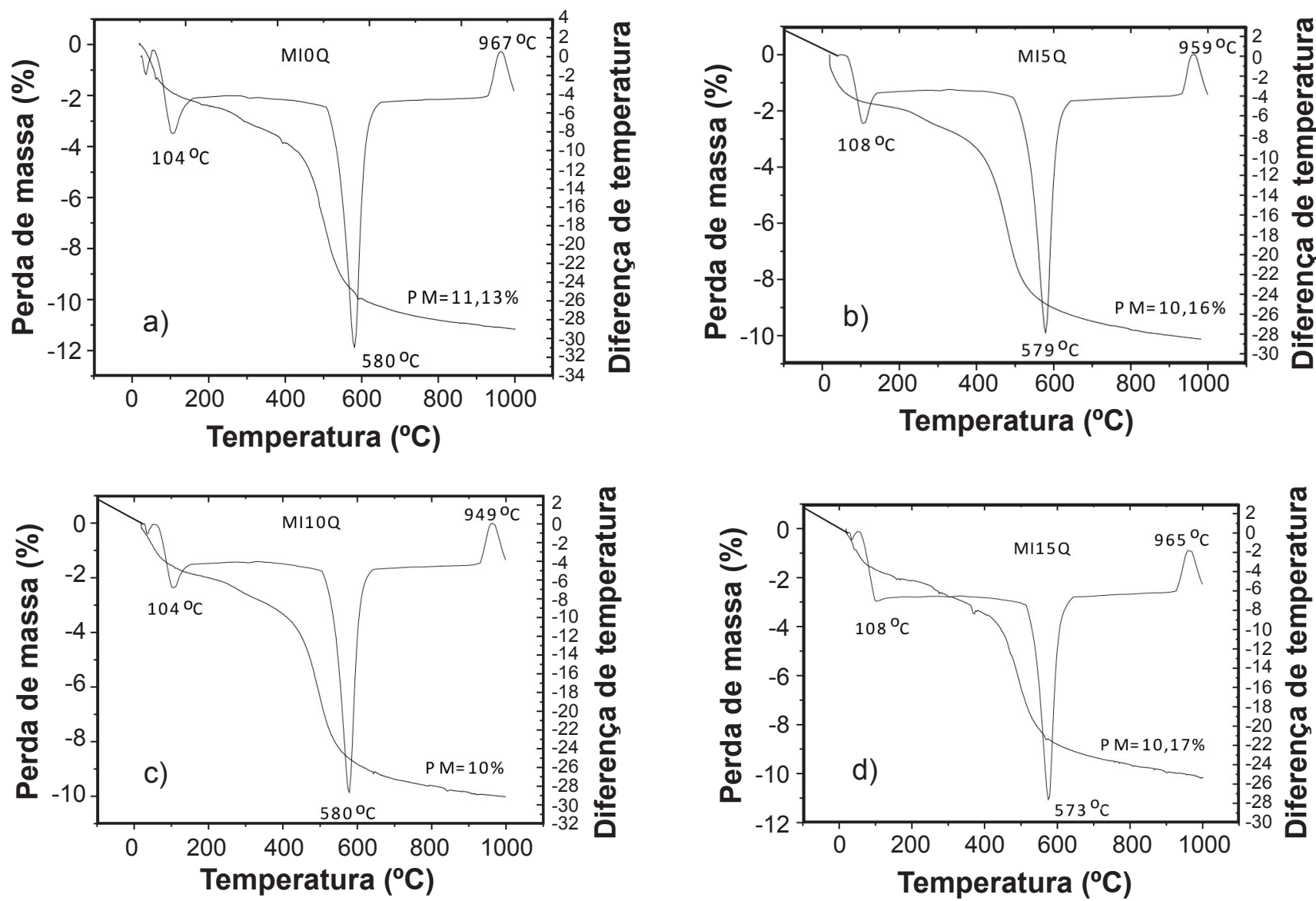

Figura 2: Curvas de ATD e ATG das massas cerâmicas com e sem adição de resíduo de quartzito.

[Figure 2: DTA and TGA curves of the ceramic masses with and without addition of quartzite waste.]

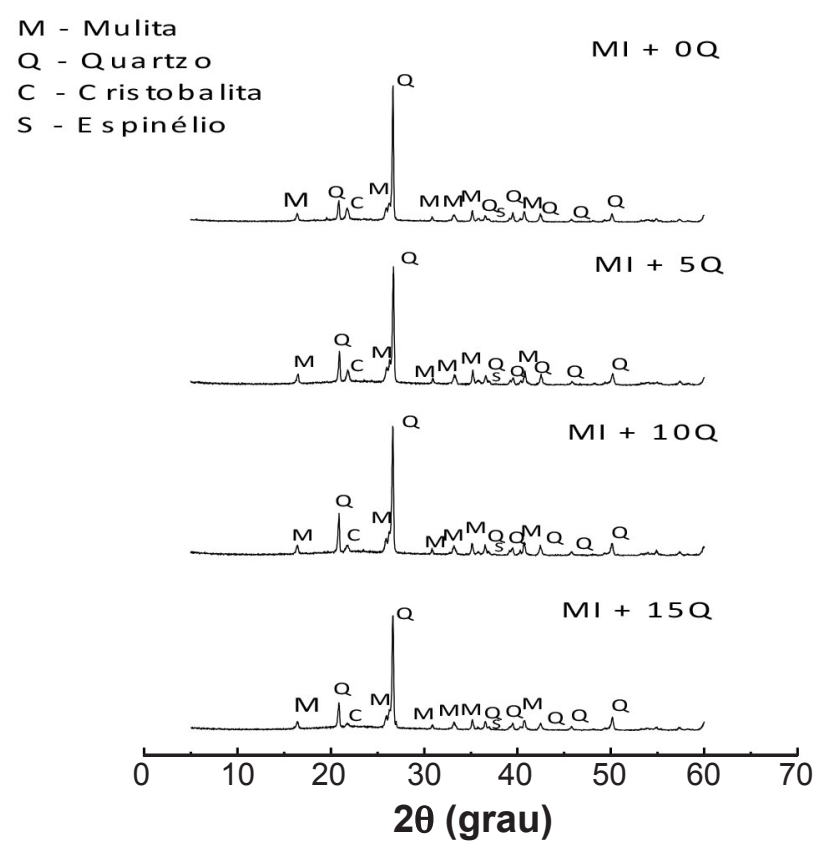

Figura 3: Difratogramas de raios $\mathrm{X}$ dos corpos cerâmicos após queima a $1200{ }^{\circ} \mathrm{C}$.

[Figure 3: X-ray diffraction patterns of ceramic bodies after firing at $1200^{\circ} \mathrm{C}$.] foram: mulita (JCPDS 15-0776), quartzo (JCPDS 46-1045), feldspato (JCPDS 89-8573), espinélio (JCPDS 82-2424) e cristobalita (JCPDS 82-0512). As fases quartzo e feldspato foram consideradas residuais, ou seja, provenientes da matéria-prima no seu estado natural. Foram detectados picos característicos da fase espinélio, cristalizada a partir da metacaulinita. Observou-se a presença de picos característicos da fase mulita. A mulita é a principal fase responsável pelas propriedades mecânicas dos produtos da cerâmica tradicional; o entrelaçamento das agulhas, a morfologia acicular e a natureza expansiva do seu mecanismo de formação são aspectos fundamentais. Também ocorreu o surgimento da fase cristobalita proveniente da transformação polimórfica do quartzo [33].

A Fig. 4a ilustra os valores da absorção de água dos corpos cerâmicos com e sem aditivação de resíduo de quartzito após queima a $850,900,950,1100$ e $1200{ }^{\circ} \mathrm{C}$. Observou-se que com o aumento da temperatura até $1200^{\circ} \mathrm{C}$ todas as composições dos corpos cerâmicos apresentaram redução significativa da absorção de água, sendo o menor valor para as massas incorporadas com $15 \%$ de resíduo de quartzito. Esse comportamento pode ser explicado pela presença de óxidos fundentes $\left(\mathrm{Fe}_{2} \mathrm{O}_{3}\right.$ e $\left.\mathrm{K}_{2} \mathrm{O}\right)$ presentes na composição química (Tabela II), pois durante o aquecimento a altas temperaturas estes fundem e preenchem os poros. 

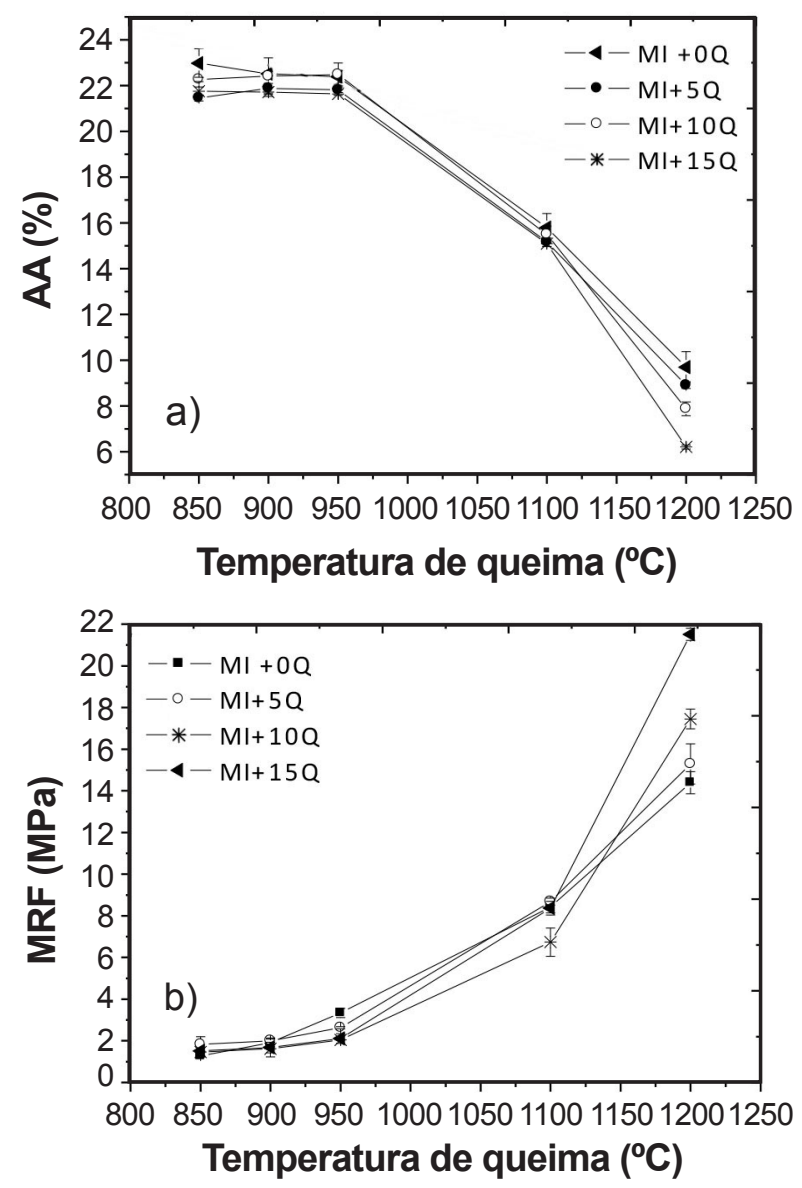

Figura 4: Absorção de água após fervura (a) e resistência à flexão (b) dos corpos cerâmicos.

[Figure 4: Water absorption after boiling (a) and flexural strength (b) of the ceramic bodies.]

Soma-se a este efeito a presença de maior quantidade de fase vítrea relacionada com a menor absorção de água das peças queimadas a $1200{ }^{\circ} \mathrm{C}$. De acordo com as normas ISO [14] e ABNT 13818 [15], os corpos cerâmicos podem ser classificados para queimas até $1100{ }^{\circ} \mathrm{C}$ como sendo revestimento do tipo poroso BIII. Para queima a $1200{ }^{\circ} \mathrm{C}$ os corpos cerâmicos podem ser classificados como sendo revestimento do tipo semiporoso $\mathrm{BIIb}$ por apresentarem valores de absorção de água entre 6 e 10\%. Valores de absorção elevados para corpos queimados em temperaturas inferiores a $1100{ }^{\circ} \mathrm{C}$ podem elevar valores de EPU fora das especificações da ABNT [15]. Os resultados corroboraram com os obtidos por [2], que estudou a incorporação de resíduo de rochas ornamentais em massas para uso em revestimentos cerâmicos.

A Fig. 4b ilustra os resultados de resistência à flexão dos corpos cerâmicos com e sem aditivação de resíduo de quartzito após queima entre 850 e $1200{ }^{\circ} \mathrm{C}$. Para todas as composições dos corpos cerâmicos, observou-se aumento de resistência com a elevação da temperatura, sendo os melhores resultados para os corpos cerâmicos incorporados com $15 \%$ de resíduo de quartzito queimados a $1200{ }^{\circ} \mathrm{C}$. Isto se deveu ao melhor empacotamento das partículas, das novas fases formadas e sua densificação, fatores que favoreceram o comportamento mecânico. Para queimas em 850 e $900{ }^{\circ} \mathrm{C}$, as peças apresentaram menor resistência (Fig. 4b). Quando massas contendo argilas e acessórios (mica, quartzo e feldspato) são submetidas a aproximadamente $1000^{\circ} \mathrm{C}$, normalmente a microestrutura final contém poucos cristais de mulita e grãos de quartzo dispersos na matriz vítrea. Analisando as temperaturas de 1100 e $1200{ }^{\circ} \mathrm{C}$, observou-se aumento significativo da resistência para todos os corpos de prova, destacando-se os obtidos com as massas contendo resíduo na temperatura de $1200{ }^{\circ} \mathrm{C}$, o que pode estar relacionado com a presença das fases mulita e espinélio (Fig. 3). Outro fator para elevação da resistência foi a presença do $\mathrm{K}_{2} \mathrm{O}$, além de maior quantidade de $\mathrm{SiO}_{2}$ e menor quantidade de $\mathrm{Al}_{2} \mathrm{O}_{3}$, fatores que podem ter contribuído para a formação do líquido eutético e a fluidez da fase líquida de menor viscosidade, acelerando a cinética das reações. Comportamento semelhante foi observado por [25, 34], que estudaram a variação microestrutural de revestimentos incorporados com resíduos de rochas ornamentais. De acordo com as normas ISO [14] e ABNT 13818 [15], as faixas de valores de resistência à flexão variam entre $18 \mathrm{e}$ $30 \mathrm{MPa}$ para os corpos cerâmicos, sendo classificados como sendo poroso BIIb. Assim, os corpos cerâmicos estudados para temperaturas inferiores a $1100{ }^{\circ} \mathrm{C}$ podem conduzir a valores de EPU elevados, ou seja, fora da especificação.

A Fig. 5 lustra a influência da temperatura de queima na expansão por umidade (EPU) para os corpos cerâmicos com e sem aditivação de resíduo de quartzito após tratamento por fervura por 24 h. Pôde-se observar que os corpos cerâmicos apresentaram valor máximo de EPU na temperatura de 1100 ${ }^{\circ} \mathrm{C}$. Este comportamento se justificou pelo fato que a elevação da temperatura de queima ocorreu com gradual aumento no teor de fase vítrea com preenchimento dos poros e também a formação de novas fases amorfas (oriundas de reações no corpo cerâmico) e, com isto, ocorreu elevação da EPU; entretanto, deve-se salientar que a temperatura de queima usual para revestimento cerâmico é superior a $1150{ }^{\circ} \mathrm{C}$, onde se verifica através da Fig. 5 diminuição nos valores de

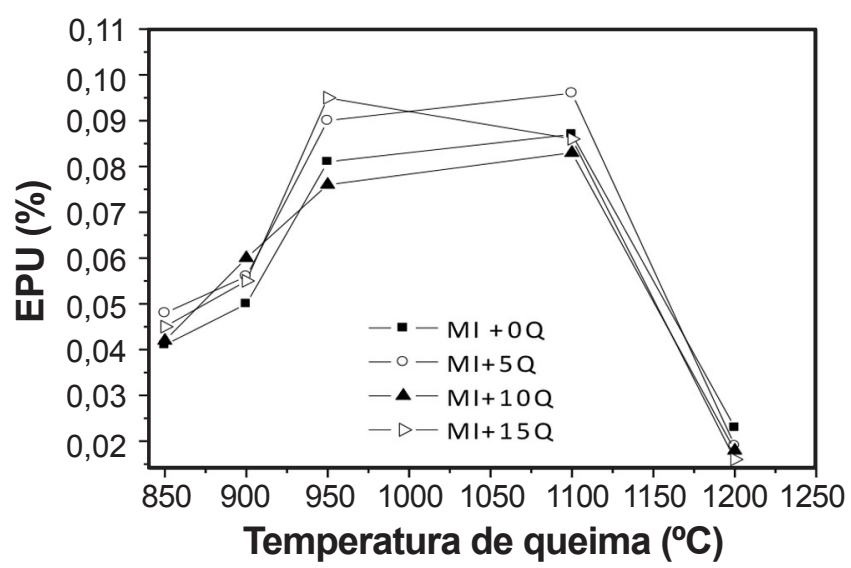

Figura 5: EPU dos corpos cerâmicos após tratamento em fervura por $24 \mathrm{~h}$.

[Figure 5: ME of the ceramic bodies after boiling water treatment for 24 h.] 
EPU. Para $1200{ }^{\circ} \mathrm{C}$ observou-se diminuição nos valores de EPU praticamente semelhantes para todas as composições estudadas; este fato pôde ser atribuído ao aumento do teor de fase vítrea e consequentemente diminuição da área específica e porosidade, enquanto que as fases amorfas formadas anteriormente transformaram-se em cristalinas e/ ou vítreas, possibilitando o efeito da redução da porosidade causando diminuição da EPU. Estudos anteriores [1, 32] sobre as reações exotérmicas que ocorrem na caulinita entre 925 e $1100{ }^{\circ} \mathrm{C}$ justificam os maiores valores de EPU ocorridos a $1100^{\circ} \mathrm{C}$ em massas cerâmicas ricas em caulinita, devido à formação de um espinélio de alumínio e silício com liberação de sílica amorfa a aproximadamente $925^{\circ} \mathrm{C}$ e à transformação do espinélio em mulita, com mais liberação de sílica amorfa na faixa de temperatura entre 1050 e 1100 ${ }^{\circ} \mathrm{C}$. Ao que tudo indica, a única certeza está no fato de haver a formação de uma fase amorfa resultante da decomposição de caulinita (pozolana) e a liberação de sílica amorfa quando da formação de mulita durante o aquecimento que é responsável pelo pico de EPU.

De modo geral, a adição do quartzito causou aumento na EPU, excetuando-se os corpos de prova queimados a 1200 ${ }^{\circ} \mathrm{C}$, onde se observou diminuição da EPU. Sendo assim, a partir das condições investigadas no presente trabalho e nos resultados apresentados na Fig. 5, teve-se que, à medida em que se aumentou a temperatura de queima de 800 até 1100 ${ }^{\circ} \mathrm{C}$, houve aumento na EPU; para $1200{ }^{\circ} \mathrm{C}$ os valores de EPU diminuíram sensivelmente para todas as composições investigadas, tornando os resultados obtidos nessa temperatura de queima bastante promissores. Comparando os resultados de EPU da Fig. 5 com o valor limite de EPU de $0,6 \mathrm{~mm} / \mathrm{m}(0,060 \%)$, proposto pelas especificações ISO [14] e ABNT NBR 13816 [15] para revestimentos cerâmicos, observou-se que os valores de EPU apresentaram-se inferiores ao limite proposto pela especificação acima citada para as amostras sinterizadas nas temperaturas entre 1100 e $1200{ }^{\circ} \mathrm{C}$. Isto evidenciou que as matérias-primas e as condições de processamento mais utilizadas no país, com temperaturas da ordem de $1200{ }^{\circ} \mathrm{C}$, potencializam o desenvolvimento de corpos com suscetibilidade para diminuir a EPU.

A Fig. 6 ilustra os resultados obtidos para a expansão por umidade (EPU) com relação à absorção de água para os corpos cerâmicos com e sem aditivação de resíduo de quartzito após fervura. Constatou-se que, para praticamente todas as amostras, à medida que a temperatura de queima aumentou, ocorreu tendência de diminuição dos valores da absorção. No entanto, a redução da absorção de água não implicou necessariamente em diminuição nos valores da EPU, com exceção da temperatura de $1200^{\circ} \mathrm{C}$, conforme já explicado anteriormente. Os resultados estão de acordo com as expectativas indicadas pela literatura $[1,2,22]$.

A Fig. 7 ilustra os resultados de resistência à flexão (MRF) em relação à absorção de água (AA) para os corpos cerâmicos com e sem aditivação de resíduo de quartzito, como forma de ilustrar as possíveis tendências. Pôde-se observar que a resistência foi, de modo geral, significativamente afetada

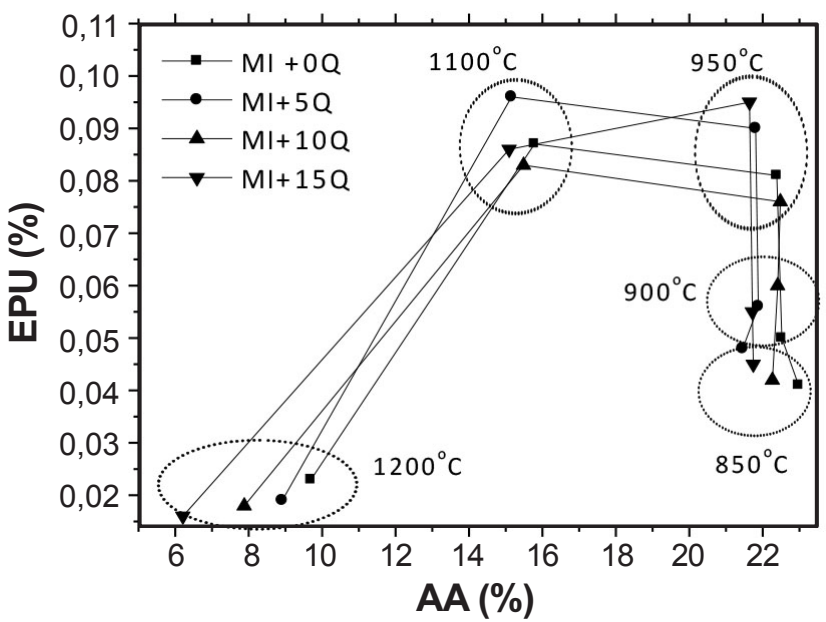

Figura 6: EPU em função da absorção de água (AA) dos corpos de cerâmicos após fervura.

[Figure 6: $M E$ as a function of water absorption (AA) of the ceramic bodies after boiling in water.]

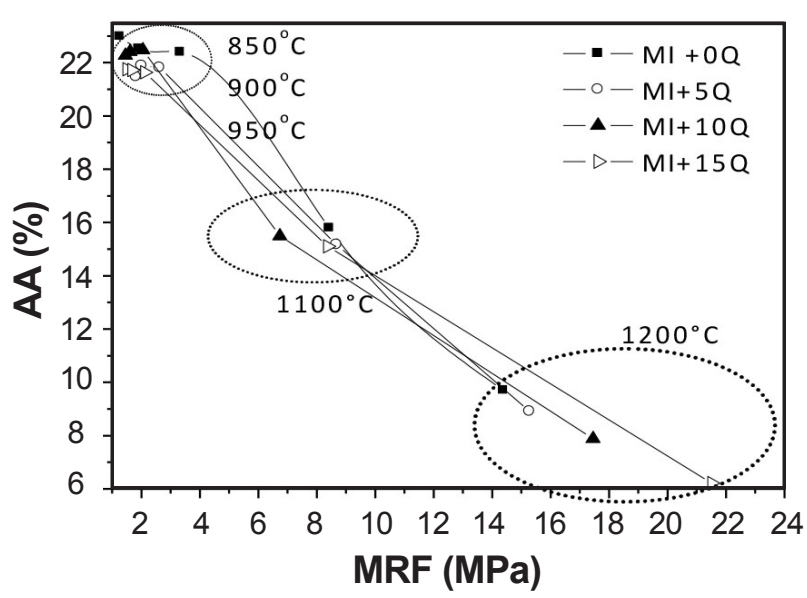

Figura 7: Relação entre resistência à flexão (MRF) e absorção de água (AA) dos corpos cerâmicos.

[Figure 7: Relationship between flexural strength (MRF) and water absorption (AA) of ceramic bodies.]

pela adição de quartzito à massa, constatando-se elevações na resistência quando do uso de 5,10 e $15 \%$ de quartzito, dependendo da temperatura de queima. Na temperatura de $1200{ }^{\circ} \mathrm{C}$ ocorreu a maior elevação da resistência à flexão das amostras, o que foi relacionado com o melhor empacotamento das partículas e menor absorção de água. Essa melhora na resistência mecânica dos corpos cerâmicos, com aditivação do quartzito, pôde ser atribuída a diminuição nos valores de absorção de água. Sabe-se que a relação entre resistência mecânica e absorção de água é altamente dependente de parâmetros cujo grau de complexidade impede a sua indicação em um modelo abrangente, devendo cada caso ser analisado através das peculiaridades que os envolvem. Esses valores foram similares aos encontrados nos estudos [1, 2, 23].

A Fig. 8 ilustra os resultados de resistência à flexão (MRF) com relação à EPU potencial dos corpos cerâmicos com e sem aditivação de resíduo de quartzito. Observaram- 


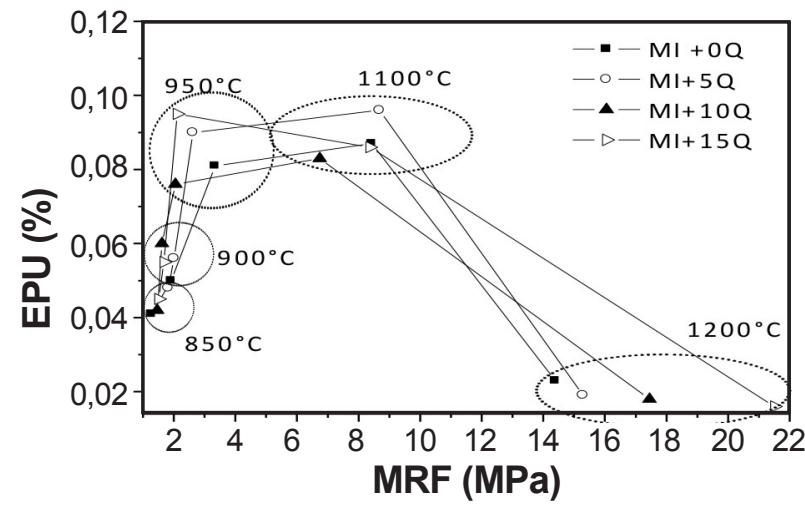

Figura 8: Relação entre resistência à flexão (MRF) e EPU dos corpos de cerâmicos.

[Figure 8: Relationship between flexural strength (MRF) and $M E$ of ceramics bodies.]

se algumas tendências bem definidas. Analisando cada composição separadamente, à medida que aumentou a temperatura de queima ocorreu um acréscimo de EPU com exceção para a temperatura de $1200{ }^{\circ} \mathrm{C}$. A adição de quartzito, de forma geral, resultou em aumento da EPU e elevação na resistência. Os corpos que apresentaram maiores reduções de EPU foram os queimados a $1200{ }^{\circ} \mathrm{C}$, onde ocorreu decréscimo gradual da EPU com a adição do resíduo. Também nesta temperatura observou-se aumento significativo da resistência mecânica para todos os corpos de prova, destacando-se os obtidos com as massas contendo resíduo, tendo provocado alterações significativas na EPU, fato este já justificado anteriormente. Esses valores foram similares aos estudos de EPU obtidos por [1, 2, 21].

\section{CONCLUSÕES}

Após os estudos de incorporação de resíduo de quartzito em uma massa utilizada na produção de revestimentos cerâmicos planos, pôde-se concluir que o resíduo poderá ser utilizado como matéria-prima alternativa para indústria cerâmica para produção de certas tipologias de revestimentos. A adição de quartzito finamente moído na massa cerâmica, nos teores investigados neste trabalho, promoveu, em geral, aumento na expansão por umidade (EPU) e na resistência mecânica à medida em que se aumentou a temperatura de queima. Todavia, para $1200{ }^{\circ} \mathrm{C}$, observou-se diminuição da EPU, desejável em se tratando de revestimentos cerâmicos. Cabe salientar que essa temperatura de queima não é usual para a maioria das tipologias de revestimentos cerâmicos; assim, para a utilização de quartzito deve-se fazer uma análise criteriosa da formulação à qual ele será aplicado.

\section{REFERÊNCIAS}

[1] R.R. Menezes, L.F. Campos, G.A. Neves, H.C. Ferreira, Cerâmica 52, 321 (2006) 1.

[2] A.M.G.D. Mendonça, J.M. Cartaxo, R.R. Menezes, L.N.L. Santana, G.A. Neves, H.C. Ferreira, Cerâmica 58, 346 (2012) 216.
[3] G.E. Merrit, C.G. Peters, J. Am. Ceram. Soc. 9, 6 (1926) 327.

[4] L.F.A. Campos, "Estudo da expansão por umidade (EPU) em blocos cerâmicos do Estado da Paraíba", Diss. de Mestrado, UFPB, Campina Grande, PB (2002).

[5] A.N. Smith, Trans. Brit. Ceram. Soc. 54, 5 (1955) 300.

[6] A.A. Milne, Trans. Brit. Ceram. Soc. 57, 3 (1958) 148.

[7] J.E. Young, W.E. Brownell, J. Am. Ceram. Soc. 42, 12 (1959) 571.

[8] F. Vaughan, A. Dinsdale, Nature 183, 4661 (1959) 600.

[9] W.F. Cole, J.P. Banks, Key Eng. Mater. 53-55 (1991) 185.

[10] L.C. Chiari, C.J. Oliveira, C. Monteiro, N.V. Forjaz, E. Biscaro, L.F. Marino, A.O. Boschi, Ceram. Ind. 1, 3 (1996) 35.

[11] F.S. Miranda, "Estudo da expansão por umidade e da resistência mecânica dos tijolos do edifício Aquarela, Jaboatão dos Guararapes", Diss. de Mestrado, UFCG, Campina Grande, PB (2001).

[12] D. Berberian, Folha de Pernambuco (2004).

[13] ASTM C370-88, "Standard test method for moisture expansion of fired whiteware products" (2011).

[14] ISO 13006, "Ceramic tiles-definitions, classification, characteristics and marking” (2012).

[15] ABNT, Assoc. Brasil. Normas Téc., NBR 13818, "Placas cerâmicas para revestimento - especificação e métodos de ensaios", Rio de Janeiro, RJ (1997).

[16] R.R. Menezes, L.F. Campos, H.C. Ferreira, H.S. Ferreira, Ceram. Ind. 10, 2 (2005) 27.

[17] F. Raupp-Pereira, D. Hotza, A.M. Segadães, J.A. Labrincha, Ceram. Int. 32 (2006) 173.

[18] R.R. Menezes, L.F. Campos, G. de A. Neves, H.C. Ferreira, Cerâmica 52, 322 (2006) 114.

[19] M. Dondi, M. Masigli, B. Fabbri, Tile Brick Int. 13, 4 (1997) 302.

[20] J.P.D. Vitorino, S.N. Monteiro, C.M.F. Vieira, Cerâmica 55, 336 (2009) 385.

[21] R.R. Menezes, L.N. Marques, L.N.L Santana, R.H.G.A. Kiminami, G.A. Neves, H.S. Ferreira, Cerâmica 56, 339 (2010) 244.

[22] L.A. Freitas, S.N. Monteiro, R. Sánchez, C.M.F. Vieira, Cerâmica 57, 342 (2011) 206.

[23] R.R. Menezes, H.S. Ferreira, G.A. Neves, H.L. Lira, H.C. Ferreira, J. Eur. Ceram. Soc. 25 (2005) 1149.

[24] M. Sutcu, H. Alptekin, E. Erdogmus, Y. Er, O. Gencel, Construc. Buil. Mater. 82 (2015) 1.

[25] M.E.A. Carreiro, "Estudo da viabilidade da incorporação de resíduo de quartzito na massa de cerâmica vermelha", Diss. Mestrado, UFCG, PB (2016).

[26] ABNT- Assoc. Brasil. Normas Téc., NBR 6459, "Determinação do limite de liquidez - método de ensaio", Rio de Janeiro (1984).

[27] ABNT- Assoc. Brasil. Normas Téc., NBR 7180, "Determinação do limite de plasticidade - método de ensaio", Rio de Janeiro (1984).

[28] P. Torres, H.R. Fernandes, S. Olhero, J.M.F. Ferreira, J. Eur. Ceram. Soc. 29 (2009) 23. 
[29] M. Dondi, Cerâmica Ind. 11 (2006) 36.

[30] A.J. Souza, B.C.A. Pinheiro, J.N.F. Holanda, J. Mater. Proc. Techn. 210 (2010) 1898.

[31] L.A. Gaspar Junior, A.F.D.C. Varajão, M.H.O. Souza, M.M.T. Moreno, Cerâmica 58, 347 (2012) 404.

[32] P. Souza Santos, Ciência e Tecnologia de Argilas, Vol. 1, 2a Ed., Edgar Blücher, S. Paulo (1992) 408.
[33] R.A. Andrade, R.R. Medeiros, L.F.A. Campos, H.S. Ferreira, R.R. Menezes, G.A. Neves, H.C. Ferreira, Cerâmica 57, 343 (2011) 329.

[34] J.P.V.T. Manhães, J.M.S. Moreira, J.N.F. Holanda, Cerâmica 55, 336 (2009) 371.

(Rec. 24/05/2016, Rev. 13/06/2016, 30/06/2016, Ac. 14/09/2016) 